\title{
Alcohol and alcohol effects: Constituting causality in alcohol epidemiology
}

\author{
Aaron Hart \& David Moore
}

\section{Keywords}

Alcohol, epidemiology, causality, effects, ontology, science and technology studies

\begin{abstract}
Taking cues from Science and Technology Studies, we examine how one type of alcohol epidemiology constitutes the causality of alcohol health effects, and how three realities are made along the way: alcohol is a stable agent that acts consistently to produce quantifiable effects; these effects may be amplified or diminished by social or other 'factors' but not mediated in other ways; and alcohol effects observable at the population level are priorities for public health. We describe how these propositions are predicated upon several simplifications and that these simplifications have political implications, including the attribution of responsibility for health effects to a pharmacological substance; the deletion of other agentic forces that might share responsibility; and a prioritization of simple effects over complex effects. We conclude by arguing that epidemiological research on alcohol might expand its range of ontological, epistemological and methodological practices to identify new ways of understanding and addressing health effects.
\end{abstract}

\section{Authors' note}

The research reported in this article was funded by the Australian Research Council (DP 110101720). The National Drug Research Institute at Curtin University is supported by funding from the Australian Government under the Substance Misuse Prevention and Service Improvement Grants Fund. We thank Paul Dietze and Robin Room for their helpful 
advice on theories of causality in alcohol epidemiology, CDP editorial board member Nancy Campbell for overseeing the review of the paper and two anonymous $C D P$ reviewers for their thoughtful and engaged comments. However, we alone remain responsible for the arguments advanced in the article. 
Epidemiology takes the improvement of population health to be its primary concern, and most epidemiological analyses of alcohol use and its effects focus on health risks (Demant, 2013; Keane, 2009). In the process of undertaking such analyses, complex assemblages of substance, bodies, relations, networks, and technology undergo processes of simplification. As Mol and Law (2002) have argued, while all knowledge practices - whether they be epidemiological, psychological or sociological - must necessarily simplify if they are to enact order and make useful statements about complex issues, the distinctive political effects of these processes of simplification are rarely considered. In this article, we draw on Science and Technology Studies (STS) to analyze the ways in which causality is constituted in one type of alcohol epidemiology - that concerned with morbidity and mortality. We argue that this subfield of alcohol epidemiology undertakes several processes of simplification to enact order and make useful statements about alcohol and its effects. First, it constitutes alcohol as a stable pharmacological agent that acts consistently and independently and causes quantifiable effects. Second, this type of epidemiology understands social or other relevant "factors" as amplifying or diminishing the intensity of alcohol consumption but as leaving the relationship between alcohol and its effects unchanged. Third, this type of epidemiology focuses on populations in order to make the effects of alcohol observable and therefore a target of public health initiatives.

There are, of course, different types of alcohol epidemiology (e.g. cohort or population studies, studies of trends in statistics, and analyses of mortality data) but we restrict our analysis to the identified type rather than to other types of alcohol epidemiology. We use our case study to begin questioning some of the dominant realities constituted by this type of alcohol epidemiology, its assumptions about what alcohol is and what it does, and the scientific authority and legitimacy granted to such work, as well as to explore some of its political effects. Further research is needed to examine how the issues we raise play out in other subfields of alcohol epidemiology. 


\section{Theoretical framework}

To conduct our analysis, we draw on recent work in STS. Over the last decade, a growing body of research has begun exploring the implications of STS for the analysis of drug use (e.g. Duff, 2011; Duff, 2012a; Duff 2012b; Duff, 2013; Dwyer \& Moore, 2013; Fraser, 2006; Fraser, 2013; Fraser \& Moore, 2011; Fraser, Moore \& Keane, 2014; Fraser \& valentine, 2008; Fraser, valentine \& Roberts, 2009; Moore, 2011; Thomson \& Moore, 2014; Vitellone, 2010; Vitellone, 2011) but its use in alcohol research is, thus far, limited (Law \& Singleton, 2003; Demant, 2009; Fraser, Moore \& Keane, 2014).

At the core of the STS approach, argues Woolgar, is an "ongoing trajectory of provocation" that aims to unsettle taken for granted assumptions about the nature of explanation (2004, p. 345). One foundational assumption challenged by STS is the binary at the heart of western metaphysics and science - the distinction between representations and that which is represented. This "Euro-American common sense realism" (Law, 2011a, p. 156) understands science, technology and medicine as the process of making increasingly accurate representations of anterior, independent entities. Law characterizes common sense realism as resting upon six assumptions: that reality is out there, independent, preceding our actions or attempts to know it, definite in form, singular and coherent (Law, 2011a). STS explicitly sets out to undo these assumptions, to "wash away the metaphysics of common sense realism", and to:

shift our understanding of the sources of the relative immutability and obduracy of the world: to move these from 'reality itself' into the choreographies of practice. (Law, 2011a, p. 172)

Law's use of the term "choreographies" draws attention to a key STS principle: that discursive and other knowledge practices do not merely describe pre-existing realities but 'enact' or 'perform' them in assemblages of material and semiotic practices (Latour, 2005; Law, 2004; Mol, 2002). Performativity focuses on the "performance of things in the world, as 
they come into encounter with various other elements in interaction so as to produce certain ontological effects" (Race, 2011, p. 410). Law (2011a) identifies five practices involved in the performance of realities: juxtaposition, ranking, selection, deletion, and framing. Juxtapositions are processes of boundary setting between categories of things: they determine taxonomic distinctions such as 'natural' and 'social' sciences, or 'human' and 'non-human' entities. Ranking refers to the application of hierarchies of salience, which is necessary to guide the selection of those entities eligible for enactment and those subject to deletion. For example, juxtapositioning, ranking and deleting occurs in quantitative social research in the identification of particular relationships between factors as statistically significant, or in qualitative research in the identification of core themes in the data. Each of these practices depends on a wider framing in which a host of realities, whose immutability and obduracy are assumed, are implied within the performance in question. Evidence of this process can be found in the literature review section of research publications, in which authors situate their inquiries within the field of already established methodologies, principles and knowledge. Law's typology directs our focus away from the question of whether research adequately represents reality and towards the question of how and why particular, partial and methodologically mediated realities have been enacted. It brings to light the contested political and philosophical positions always more or less implicit in scientific epistemology and methodology.

Of particular significance to our present task is Law's (2011a) notion of "collateral realities", a concept first applied in the drug field in Fraser's (2013) analysis of obesity and the neuroscience of addiction, and further elaborated in Fraser, Moore and Keane's (2014) analysis of changing definitions of addiction. Collateral realities are "backstage assumptions" (Law, 2011b, p. 493) - that is, those that appear incontestable and therefore beyond debate. They are realities that:

get done incidentally, and along the way. They are realities that get done, for the most part, unintentionally. They are realities that may be obnoxious. Importantly, 
they are realities that could be different. It follows that they are realities that are through and through political. (Law, 2011a, p.156)

Furthermore:

If reality appears (as it usually does) to be independent, prior, definite, singular or coherent then this is because it is being done that way. Indeed these attributes or assumptions become examples, amongst others, of collateral realities. (Law, 2011a, p. 156)

For Law, the stabilizing role of collateral realities is crucial because "it is the endless enactment of collateral realities that tends to hold things steady" (2011a, p. 172). Identifying collateral realities and the inconsistencies and tensions between these stabilizing practices and the realities they perform offers a useful entry point for questioning existing accounts and offering new ones.

The final conceptual apparatus required for the present analysis is the assemblage or actor network. Assemblages are the agential unit in an STS conceptual model of causation that differs from that produced in the type of alcohol epidemiology we analyze in the next section. Reviewing After Method (Law, 2004), Duff summarises Law's approach to agency:

Law distributes or spatializes agency, attributing it both to (human) actors understood in a conventional sense, and to "actants" regarded as any nonhuman entity, object, substance, or process that makes a difference in a network of force relations or actions/behaviors. (2012a, p. 271)

Causation in the STS model results from the agency of assemblages, or "networks of force relations", which comprise human actors and non-human actants. For our purposes, an assemblage is defined as an array of human and non-human agents which interact as a network to cause a situation to change in some detectable way. Significantly, the agency of an assemblage is not attributable to the sum of its parts - that is, where each actant is understood as an "intermediary" that "transports meaning or force without transformation: defining its inputs is enough to define its outputs" (Latour, 2005, p. 39). Rather, the role of 
each actor and actant in an assemblage is understood as one of mediation. For mediators, "their input is never a good predictor of their output" because "mediators transform, translate, distort, and modify the meaning or the elements they are supposed to carry" (Latour, 2005, p. 39). In this model, causation is emergent rather than determined and belongs to the assemblage rather than to its components. In this context, Duff argues that it makes little sense "to attempt to determine the degree of causality attributable to any one body, actor or object within a network, because the network produces activity as an emergent effect of all associations immanent to it" $(2013$, p. 2). The emphasis shifts from identifying the agency of individual agents (whether human or non-human) to identifying the plethora of entities at work in the assemblage and to the relations between them.

For STS scholars, the delineations between individual actors and actants in any assemblage, and between their causes and effects, can be scientifically enacted in a multitude of ways. This approach to causality positions causes and effects as ontologically inseparable from epistemological practices. Latour argues that "causes and effects are only a retrospective way of interpreting events" (2005, p. 39). To put it another way, where effects are "caused" by alcohol use, systems for the definition and measurement of effects are as much a pre-condition for these effects as alcohol itself. These systems of definition and measurement also enact a particular version of alcohol which, in each case, might be done differently. What then of an STS-informed epistemology of cause and effect? On this question, Latour argues that:

A good ANT account is a narrative or a description or a proposition where all the actors do something and don't just sit there. Instead of simply transporting effects without transforming them, each of the points in the text may become a bifurcation, an event, or the origin of a new translation... In a bad text only a handful of actors will be designated as the causes of all the others, which will have no other function than to serve as a backdrop or relay for the flows of causal efficacy. (2005, p. 128) 
Here Latour argues for epistemological practices that account for agential forces making a difference on multiple planes simultaneously. For example, research identifying "risk factors" that dispose young adults to heavy sessional drinking practices should also consider the ways that these "factors" alter the effects of alcohol, in addition to the ways in which they increase the intensity of consumption. Duff provides an example of how this perspective might be used when he identifies several agential forces relevant to the study of injecting drug use:

the presence of the drug itself as an agent; the human body amid other bodies; the needle and the syringe; cultural conventions governing the course of drug consumption; the spatial circumstances of the event ... among an everramifying throng of "actants" and agencies. (Duff, 2012a, p. 271)

In the assemblage model, each of these agents potentially mediates the effect of the injected drug; the drug itself is not a stable agentic force but one of a 'throng' of forces co-constituting the drug effect.

An empirical example applying this theory of cause and effect is Gomart's (2002) analysis of two studies of methadone treatment: one in France and the other in the US. She argued that the differences in methadone's effects between the two sites could not be accounted for by differences in interpretation or by the inherent properties of the drug. In the American experiment, methadone acted to block heroin craving, whereas in the French experiment, it acted to facilitate the interventions of psychiatrists. To make sense of these different drug effects, Gomart focuses on the theoretical and clinical assemblages enacting the drug within the trials. Each action emerged from an assemblage enacting a particular drug use pathology. Methadone in each trial acted differently through an assemblage of different practices, and its effects varied as the practices varied. She concluded that methadone can only be defined in relation to the specific assemblages of practice engaged each time in its enactment. For Gomart, the effect is the substance and the substance cannot be understood 
in isolation from its practice, just as any other material object cannot be understood in isolation from its associated practices:

The sheer multiplicity of differences makes it impossible to hold that substance is constant, whereas interpretations vary. Even entities which had seemed indivisible, foundational, are shown to be achievements, shaped in and through practices. (Gomart, 2002, pp. 97-98)

Applying Gomart's analysis to the alcohol field, we can say that alcohol effects always emerge from assemblages of, among other things, drinking practices and the material arrangements of specific settings. Alcohol does not have stable properties or characteristics: it has effects and these effects are always co-constituted by the human and non-human agents making a difference in the events of alcohol consumption. In this model of causality, the epistemological task for research on "alcohol-related problems" becomes identifying "what kinds of associations, between what kinds of actors, objects, entitles, actants and forces, are involved in the production of these problems" and how these associations might be transformed in efforts to reduce harm (Duff, 2013, p. 3).

In the sections that follow, we draw on the STS concepts of performativity, collateral realities, stabilization, and emergent causality to analyze the type of alcohol epidemiology concerned with morbidity and mortality.

\section{The epidemiology of 'alcohol-caused' morbidity and mortality}

We begin our analysis by focusing on a landmark text in the type of alcohol epidemiology concerned with morbidity and mortality, that of English and colleagues (English, Holman, Milne, Winter, Hulse, Bower et al., 1995). There are good reasons to treat this report as a key site in the constitution of causality. Described as a "seminal work" in an international review of research investigating the relationship between alcohol consumption and the global burden of disease, published in leading scientific journal Addiction (Rehm, Baliunas, 
Borges, Graham, Irving, Kehoe, et al., 2009), the report's methodology and findings have had a lasting legacy, with 628 citations in Google Scholar (search conducted on 20 March 2014) and re-iterations appearing in national studies of costs, harms and patterns of alcohol use (e.g. Chikritzhs, Catalano, Stockwell, Donath, Ngo, Young, \& Matthews, 2003; Collins \& Lapsley, 2008; Laslett, Room, Ferris, Wilkinson, Livingston, \& Mugavin, 2011; Sjögren, Eriksson, Broström, \& Ahlm, 2000) English et al.'s method for assessing "the evidence of causality between alcohol consumption and disease outcomes" was also used in a WHO report on the Global Burden of Disease project (Rehm, Room, Monteiro, Gmel, Graham, Rehn, et al., 2004, p. 34). A exhaustive international summary of alcohol research, described as the "alcohol policy bible" (Babor, Caetano, Casswell, Edwards, Giesbrecht, et al. 2010, p. 8), draws on English et al.'s epidemiological findings on alcohol consumption and heart disease (p. 121) and breast cancer (p. 125). It also cites other articles that employ English et al.'s model of causality (e.g. Rehm, Mathers, Popova, Thavorncharoensap, Teerawattananon, et al., 2009). English et al.'s (1995) methodology has been revised for some diseases but has remained mostly intact in updated versions of the publication, the most recent of which was authored by Ridolfo and Stevenson (2001).

In explaining some guiding principles for the etiology of alcohol and other drug morbidity and mortality, English et al. state:

The term "drug caused" is used in preference to "drug related" or "drug associated" because it is considered that the connection between deaths and morbid events so described, and the drugs to which our enquiry directed, is correctly expressed as causal. $(1995$, p. 6)

In determining that causation is an appropriate characterization of the relationship between alcohol and other drug use and mortality and morbidity, English et al. draw on a body of theoretical work within epidemiology. Causality is a topic of significant conjecture within epidemiology (Ward 2009). According to Abbot (1998), common points of difference in models of causation include: singular versus multiple causes; necessary versus sufficient 
causes; rational action versus mechanical determination; simultaneous versus sequential ordering; and deterministic versus probabilistic agency. Room and Rossow highlight the significance of these differences of theory in the alcohol field when they note that: "[w]hile analysts have differed on whether alcohol causes crime, the differences primarily reflect varying definitions of causation" (2001, p. 218). English et al. apply a model of causation first proposed by Rothman, which he described as an "intuitive base for causal thinking" (Rothman, 1976, p. 591). For Rothman:

A cause is an act or event or a state of nature which initiates or permits, alone or in conjunction with other causes, a sequence of events resulting in an effect. (1976, p. 588)

In Rothman's model, disease arises from "sufficient causes", which typically comprise multiple "component causes". Component causes of interest may be necessary (i.e. without which the disease would never occur) or unnecessary (i.e. without which the disease would still sometimes occur). Both are of epidemiological interest if they co-occur with the disease at high frequency. Using Rothman's model, English et al. elaborate the specific causal relationship between alcohol and other drugs ("drugs") and their effects: "in the amounts usually consumed, drugs are component causes rather than sufficient causes of death and illness", and "except for conditions defined on the circular basis of their cause, drugs are rarely, perhaps never a necessary cause of death and illness" (1995, p. 6). Rather than identifying necessary causes, the task of epidemiology in Rothman's model is to identify component causes of "public health importance" (1976, p. 588), that is, those that are present in a high fraction of disease instances in a given population. Rothman has performed a permissive definition of "cause" which could conceivably include just about anything. Applying Law's typology of stabilizing practices to English et al.'s etiology, we can see that "causes" in Rothman's model are not selected or ranked - this process is instead deferred to the designation of agents of "public health importance". Here, the salience of various agents must be performed via a fraction of disease instances in a given population. 
Most causes will be deleted, and a few selected for the attention of public health practitioners. Alcohol's designation as an agent of public health importance was to a great extent already achieved by the performance of the study itself.

There are, however, competing theories of causation in epidemiology. For example, the "Bradford Hill criteria" is a logical test used for justifying a move from observing a statistical association between phenomena to a verdict of causation. The nine criteria - consistency, strength, specificity, temporal relationship, coherence of association, gradient, plausibility, experiment and analogy - are deemed to provide "the context for making a logical, albeit non-deductive and non-inductive, inference to a hypothesis that (best) explains the facts" (Ward, 2009, p. 16). According to their author (Hill, 1965, cited in Ward, 2009, p. 14), the Bradford Hill criteria assist researchers to determine if there "is any other way of explaining the set of facts before us, is there any other answer equally, or more, likely than cause and effect?". The Bradford Hill criteria constitute "arguably the most commonly-used method of interpreting scientific evidence in public health" (Weed, 2004, cited in Ward, 2009, p. 6) and establish a strict test for any agent to pass before it is deemed to be a "cause" of disease. English et al. do not explain why they chose Rothman's model of causation from among those available, and we might speculate on the political implications of using the Bradford Hill criteria and failing to demonstrate that alcohol is a "cause" of disease in this stricter sense. In any case, those encountering English et al.'s categorization of alcohol as a "cause" of disease without familiarity with Rothman's model might credit the term "cause" with undue significance as a result of the hegemony of the Bradford Hill criteria.

Epidemiology does not typically attempt to understand causal mechanisms in their entirety, but attempts to identify causes nearest to the specified outcome and most amenable to practical intervention (Krieger, 1994). In order to isolate the causal agency of alcohol among the assemblage of agents potentially involved, English et al. use aetiological fraction methodology and provide the following justification: 
Because of incomplete knowledge or inability to identify other component causes, it is often difficult or impossible to determine in which individual cases of death or illness a drug was a component or cause. In such cases, the causal relationship between adverse health effects and drug use must be expressed in terms of a probability measure known as the aetiologic fraction. These fractions underlie most of our calculations of drug caused death and morbid events. (1995, p. 7)

Aetiological fractions are calculated in two steps: the first to establish "relative risk" and the second to apply it to the population. Relative risk is the risk of harm "in" drinkers relative to the risk of harm in abstainers or low volume drinkers, and is established by studies of the prevalence of certain diseases or conditions in both cohorts. Often, meta-analyses rather than single studies are used to determine a pooled estimate of the relative risk. For example, Ridolfo and Stevenson (2001), whose study updated some of English et al.'s (1995) findings, use data from 39 international studies to show that the aetiological fraction attributable to drinking for breast cancer among females aged 18 and over was 0.121 (12\%). In this first move, English et al., and Ridolfo and Stevenson, refigure agents such as alcohol as "riskfactors" and causation is located instead with disease, as classified by the World Health Organization's International Classification of Diseases (ICD-9).

Once relative risks have been constructed, the second move is the translation of relative risk into effects at the population level. Ridolfo and Stevenson explain the process as follows:

a probability measure of the likelihood of causation by the risk factor...[is] applied to the total number of deaths, illnesses or injuries resulting from a specific cause. (2001, p. 2)

This process often involves aggregating the various classifications of disease into more general categories. For example, Ridolfo and Stevenson (2001) do not give a figure for female breast cancer specifically but find that, in 1998, 485 cancer-caused deaths among Australian females were "attributable" to alcohol use (p. 97). The use of the term 
"attributable" here is crucial - it resolves the ambiguity around alcohol's status as a component cause and elevates it to the status of a necessary one for the 485 cancer cases. It is important to note that, for diseases such as cancer, alcohol is constituted as a necessary cause of disease at the population level rather than in individual cases.

\section{Stable agents, mediators and populations}

Let us consider these moves to stabilise alcohol's causality from the perspective of Law's (2011a) choreographies of practice. First, alcohol is juxtaposed with all the other components of a sufficient cause of disease and thus performed as a stable, individuated pharmacological agent. Second, alcohol is ranked and selected as an agent of public health importance by the performance of the study itself. Third, the other component agents (in a sufficient cause of death or disease) are deleted from the causal equation through relative risk calculations such as the $12 \%$ figure for breast cancer. Finally, by applying the relative risk to the population and deducing the "attributable" mortality and morbidity figures, alcohol is performed as out there, independent, preceding our actions or attempts to know it, definite in form, singular and coherent (Law, 2011a). Through a choreography of practices, a reality of alcohol as a cause of death and disease has been performed and stabilized.

English et al. (1995), and the studies that draw on this work, perform three collateral realities of alcohol. First, alcohol is a stable pharmacological agent that acts independently and consistently and produces quantifiable effects. With this reality stabilized, subsequent studies and reviews take alcohol's status as a cause of death and disease to frame their further propositions. For example, consider the following statement from Australia's National Health and Medical Research Council (NHMRC):

Alcohol consumption accounted for 3.3 per cent of the total burden of disease and injury in Australia in 2003. (NHMRC, 2009, p. 27)

To develop these figures, the NHMRC use English et al. as a source of the injury categories for which alcohol has an "accepted causal effect". In the international context, the WHO 
report on the Global Burden of Disease project cited earlier states:

alcohol-related burden of disease is considerable: $3.2 \%$ of global mortality and $4.0 \%$ of the global burden of disease measured in [disability-adjusted life years]. (Rehm et al., 2004, p. 12)

Both of these statements contain reifications of English et al.'s (1995) performance of alcohol's agency. Once it has been quantified, alcohol's agency is rendered immutable, stable and ready to be deployed as a fixed substrate in further elaborations.

The second collateral reality emerging from the epidemiological constitution of alcohol effects, one that helps to support the first collateral reality that alcohol is a stable agent, is that social or other "factors", such as socio-economic status or geographic location, are understood to amplify or diminish - in Latour's terms "transport ... without transformation" the force of alcohol effects. But these factors are held at arms-length from causation; it is only alcohol that causes alcohol effects. Instead these intermediary factors are related to alcohol effects via their influence on the volume and frequency of alcohol use.

Instances of the tendency to constitute social factors as intermediaries can be found a wide range of epidemiological work on alcohol. Take the following example of the intermediary role ascribed to employment, or "labour force status", in an Australian survey study deploying epidemiological findings in its methodology. This study was commissioned by the Australian Institute of Health and Welfare (AlHW), a statutory body charged with reporting the state of the nation's health. As such it has a direct role in informing the development of public health research and policy in Australia. The AlHW's 2010 National Drug Strategy Household Survey reported that:

employed people were more likely than unemployed people or those not in the labour force to drink at levels that placed them at risk of ... alcoholrelated injury on a single drinking occasion (30.4\% at least yearly but not weekly, and $20.1 \%$ at least weekly) [emphasis added]. (AlHW, 2011, p. 59) 
To develop these figures, the AlHW used the NHMRC's figures for the number of drinks per occasion. The NHMRC's figures, as we mentioned above, deployed English et al.'s injury categories. In these results, the relationship between employment and the health effects of concern can be characterised in the following steps: (1) employed people were more likely to drink heavily on single occasions, and (2) those who were more likely to drink heavily on a single occasion were more likely to sustain an "alcohol related injury" (where alcohol related injuries are constructed through relative risk methodology). Employment here does not have a direct causal relationship with the health effects in question, rather it serves an intermediary role - to amplify or diminish the volume of alcohol consumed. The AlHW (2011) report constitutes the causal relationships between alcohol, health effects and a range of other "social characteristics" - such as education, main language spoken at home, socioeconomic status, geography, marital status, and Indigenous status - in a similar way. These factors are also understood as amplifying or diminishing alcohol consumption rather than as having direct causal relationships with health effects.

Other epidemiological studies on alcohol also constitute social factors as intermediaries that shape alcohol consumption. Examples of this trend include studies of age, gender, cultural background, recreational spending money, life stage, living situation, family conflict and age at first drink (Livingston, Laslett \& Dietze, 2008); residence in an area of income inequality (Karriker-Jaffe, Roberts \& Bond, 2012) and moral perceptions of alcohol use (Amonini \& Donovan, 2006). The proliferation of studies in which the level of alcohol consumption is figured as a proxy for health effects has not gone unnoticed. Jayne, Valentine and Holloway (2011) note the increasing focus on consumption 'units' in public health studies of alcohol and conclude that, since the 1990s, they have become 'the accepted standardized method for measuring individual consumption and assessing problematic drinking' (original emphasis, p. 830).

Yet there are good reasons to consider whether social factors, as elements in assemblages 
involving alcohol, might also act as mediators capable of transforming alcohol effects rather than merely intermediaries modulating their force. Taking the example of employment, heavy drinking is sometimes practiced as a "cathartic release from the working week" (Measham, 2004, p. 321) and has historically been associated with Australian masculine ideals of the "work and bust" cycle of prolonged hard work followed by extended drinking sessions (Roche et al., 2008). In this sense, employment acts in an assemblage with labour markets, Australian masculinity and alcohol to produce alcohol effects of normative compliance with dominant modes of production. These effects are likely to enhance the social integration of drinkers which, in turn, may affect lifestyle and health. The complex interplay of alcohol use, social integration and mortality and morbidity has been explored by Skog (1996), who called for greater attention to "social factors" within alcohol epidemiology. On the other side of the coin, unemployment also mediates alcohol effects but in different ways. Fraser and valentine argue that in the context of neo-liberalism, "those who receive income support are no longer classed as citizens with entitlements from the state to meet their needs, but supplicants in need of charity and psychological intervention" (2008, p. 15). This dynamic arguably renders heavy drinking among unemployed welfare recipients as abject rather than normative, and denies them the socially integrative function alcohol serves among workers. Room (2005) showed an increased level of harm for any given level of alcohol and other drug use among those experiencing poverty, and argued that marginalization and stigma commonly add to this effect. In this sense, employment (and its corollary, unemployment) can be shown to mediate alcohol effects and "become a bifurcation, an event, or the origin of a new translation" (Latour, 2005, p. 128). Similar arguments might be made for investigating other elements in alcohol assemblages that are typically assigned intermediary roles, but these realities tend to be deleted by epidemiological processes of simplification.

The third collateral reality emerging from the epidemiological enactments of alcohol under examination here is that its effects are most visible at the population level, rather than in individual cases, and therefore a worthy target of public health initiatives. English et al. 
(1995) recognise that "it is often difficult or impossible to determine in which individual cases of death or illness a drug was a component or cause" so instead use probability measures at the population level to characterize alcohol's agency (English et al., 1995, p. 7). Krieger (1994) distinguishes the causes of health effects at the population level from those in individuals, and argues that insights from epidemiological research are not necessarily applicable to individuals. Rothman (1976) is careful to point out that his model aims to inform public health at the population level, and cannot be meaningfully applied to individual cases. This is because it does not focus attention on components with a universal basis (i.e. necessary causes). Indeed, Rothman acknowledges that "the occurrence of disease in any individual involves a collection of component causes which constitute a sufficient cause that is unique, by its complexity" (1976, p. 592). The implication here is that while alcohol acts on individuals in complex ways, it acts on populations in simple ways, calling into question the meaningfulness of epidemiological research for individual members of populations. Despite this limitation, population data are routinely used to advise individual drinkers, such as in the case of the Australian National Health and Medical Research Council's (2009) Australian Guidelines to Reduce Health Risks from Drinking Alcohol. The realist conception of a population is as a scaled up representation of multiple individuals, but in light of the insights of STS, a population is an entity whose existence is mediated by epidemiological science as much as it is by the collection of individuals it seeks to represent. A population is an abstraction emerging from a choreography of scientific practice. Mol (2002) identifies differences and frictions between treatments of benefit to populations and treatments of benefit to individuals. In principal, she says, we can do both, but in practice, public money, limited as it is, can only be spent once, and therefore difficult choices must be made about what kinds of entities we are treating.

\section{Conclusion}

In this article, we have traced some of the processes of simplification involved in one type of epidemiological enactment of alcohol and its effects. The stabilizing of alcohol as "causing" 
"deaths and morbid events" "in preference" to being "associated with" or "related to" these outcomes is aided by the constitution of three collateral realities: alcohol is a stable pharmacological agent that acts independently and consistently and produces quantifiable effects; social or other "factors" may amplify or diminish the force of alcohol effects by altering the volume of alcohol consumed but not the causal relationship between alcohol and its effects; and alcohol effects are most visible at the population level and therefore populations rather than individuals are the entity of primary public health concern.

What political effects might result from these simplifications? Alcohol - its pharmacology, its effects on bodies, its agency - is prioritised. This, of course, is understandable given that public health relies principally on alcohol availability strategies - that is, regulating the substance through taxation, reducing trading hours or the number of licensed premises, lowering the geographical density of liquor outlets, and so on - as its primary tool. And, as we noted above (citing Mol), public money can only be spent once. But this type of epidemiological research and the public health policy it encourages also continue to materialise alcohol as a powerful (somewhat malign) agent capable of "causing" unwanted outcomes. In this, there are echoes of a long-established way of understanding alcohol and other drug problems: as arising from the power of the substance to erase reason and rationality, and to produce disinhibition and "irresponsible" conduct on the part of its consumers.

In Law's terms, this type of alcohol epidemiology makes present and visible the powerful agency of alcohol - alcohol as non-human actant capable of making things happen. But this visibility, this making present, also serves to delete, to render less visible, other aspects of the assemblages in which alcohol acts. Cultural and social studies constitute alcohol and drinking as gendered practice; a temporary freedom from life's problems; a fondly and oftrecalled memory; an appropriate act in a particular time and place; a risk behavior; a transport problem; a consequence of lax regulation; an enactment of class; a demonstration 
of risk-taking competency; a response to trauma or boredom; a risk to employment; a factor in court hearings; an overdose risk; a burden on family relationships; a response to controlling use of other drugs; a lapse after treatment, and so on.

Alcohol, in other words, never acts alone - it is always a component of a sufficient cause (or an actant in an assemblage). Where harm, injury, morbidity and mortality are attributed to the agency of an assemblage in which alcohol is present, there will always be epistemological choices to make about which actants should be made present and which absent, and which collateral realities should be reified and which contested. These choices will distribute responsibility for "the problem" (however it might be enacted) in a particular way, with ramifications for public health policy and service provision. For example, Demant and Krarup (2013) show how Danish research, policy regulation and public concern around adolescent binge drinking have worked in parallel to enact alcohol as an actant of moral and cultural significance. These enactments have reinforced a liberal regulatory regime and displaced enactments of alcohol as a socio-material actant with, among other things, longterm health effects. In light of the insights of STS, any distribution of responsibility is partial, methodologically mediated and contestable. Studies might more explicitly recognize their epistemological practices as participating in an ontological politics (Mol, 1999; Law, 2004) with political and policy implications. For example, studies of alcohol's effects on populations might be more explicit about their role in obscuring other realities about alcohol's effects on individuals and groups. Alcohol studies might also seek to expand the range of realities they enact rather than further reinforcing already well-ossified collateral realities.

Latour (2004, p. 221) argues that scientific agendas are inevitably undermined by the multiplicity of realities: "there is no primary quality, no scientist can be reductionist, disciplines can only add to the world and almost never subtract phenomena" (2004a, p. 227). Further, he calls for an expansionary ontological agenda: generalisations should be a vehicle for travelling through as many 
differences as possible - thus maximising articulations - and not a way of decreasing the number of alternative versions of the same phenomena.

(Latour, 2004, p. 221)

We might contribute to the ontological range of alcohol public health research by following Duff's suggestion to identify "what kinds of associations, between what kinds of actors, objects, entitles, actants and forces, are involved in the production of [alcohol] problems" and how these associations might be transformed in efforts to reduce harm (Duff, 2013, p. 3). While there is no doubt a qualitative dimension to this task, quantitative researchers might construct some innovative methods to test the patterns identified in small groups against a broader population (Agar, 1996). While these findings would not necessarily provide causal insights, detailed descriptions of patterns of associations can highlight the limits and possibilities for intervention (Abbot, 1998, p. 176). With a wider repertoire of ontological, epistemological and methodological practices, alcohol research and policy might begin to identify new ways of understanding and responding to the varied assemblages within which alcohol produces health effects. .

\section{References}

Abbot, A. (1998). The causal devolution. Sociological Methods \& Research, 27(2), 148-181.

Amonini, Claudia, \& Donovan, Robert J. (2006). The relationship between youth's moral and legal perceptions of alcohol, tobacco and marijuana and use of these substances. Health Education Research, 21(2), 276-286.

Australian Institute of Health and Welfare. (2011). 2010 National Drug Strategy Household Survey report. Drug statistics series. Canberra: AlHW.

Australian Institute of Health and Welfare. (2002). 2001 National Drug Strategy Household Survey: detailed findings. Drug statistics series. Canberra: AlHW.

Babor, Thomas, Caetano, Raul, Casswell, Sally, Edwards, Griffith, Giesbrecht, Norman, Graham, Kathryn, . . Rossow, Ingeborg. (2010). Alcohol: No ordinary commodity: Research 
and public policy (2nd ed.). Oxford: Oxford University Press.

Chikritzhs, Tanya, Catalano, Paul, Stockwell, Tim, Donath, Susan, Ngo, Hanh, Young, Deidra, \& Matthews, Sharon. (2003). Australian Alcohol Indicators 1990-2001: Patterns of Alcohol Use and Related Harms for Australian States and Territories. Perth: National Drug Research Institute.

Collins, David J., \& Lapsley, Helen M. (2008). The Costs of Tobacco, Alcohol and Illicit Drug Abuse to Australian Society in 2004/05. Canberra: Department of Health and Ageing.

Demant, Jakob. (2009). When Alcohol Acts: An Actor-Network Approach to Teenagers, Alcohol and Parties. Body \& Society, 15(1), 25-46

Demant, Jakob. (2013). Affected in the nightclub. A case study of regular clubbers' conflictual practices in nightclubs. International Journal of Drug Policy, 24, 196-202.

Demant, Jakob, \& Krarup, T. M. (2013). The structural configurations of alcohol in Denmark: Policy, culture, and industry. Contemporary Drug Problems, 40(2), 259-289.

Duff, Cameron. (2011). Reassembling (social) contexts: New directions for a sociology of drugs. International Journal of Drug Policy, 22(6), 404-406

Duff, Cameron. (2012a). BOOK REVIEW ESSAY: After methods, after subjects, after drugs. Contemporary Drug Problems, 39(2), 265-193.

Duff, Cameron. (2012b). Accounting for context: exploring the role of objects and spaces in the consumption of alcohol and other drugs. Social \& Cultural Geography, 13(2), 145-159.

Duff, Cameron. (2013). The social life of drugs. The International Journal of Drug Policy, 24(3), 167-172.

Dwyer, Robyn, \& Moore, David. (2010). Beyond neoclassical economics: Social process, agency and the maintenance of order in an Australian illicit drug marketplace. International Journal of Drug Policy, 21(5), 390-398.

English, DR, Holman, CDJ, Milne, E, Winter, M.G., Hulse, G.K, Bower, C.I., . . Ryan, G.A. (1995). The quantification of drug caused morbidity and mortality in Australia. Canberra: Commonwealth Department of Human Services and Health.

Fraser, Suzanne. (2006). The chronotope of the queue: Methadone maintenance treatment and the production of time, space and subjects. International Journal of Drug Policy, 17(3), 192-202. 
Fraser, Suzanne. (2013). Junk: Overeating and obesity and the neuroscience of addiction. Addiction Research \& Theory, 21(6), 496-506

Fraser, Suzanne, \& Moore, David. (2011). Constructing drugs and addiction. In S. Fraser \& D. Moore (Eds.), The Drug Effect. New York: Cambridge University Press.

Fraser, S., Moore, D. \& Keane, H. (2014). Habits: Remaking Addiction. Basingstoke: Palgrave Macmillan.

Fraser, S., \& valentine, k. (2008). Substance and Substitution : Methadone Subjects in Liberal Societies. New York: Palgrave Macmillan Ltd.

Fraser, Suzanne, valentine, kylie, \& Roberts, Celia. (2009). Living Drugs. Science as Culture, 18(2), 123-131

Gomart, Emilie. (2002). Methadone: Six Effects in Search of a Substance. Social Studies of Science, 32(1), 93-135.

Hill, A. (1965). The Environment and Disease: Association or Causation? Proceedings of the Royal Society of Medicine, 58, 295-300

Jayne, Mark, Valentine, Gill, \& Holloway, Sarah L. (2011). What Use Are Units? Critical Geographies of Alcohol Policy. Antipode, 44(3), 828-846.

Karriker-Jaffe, Katherine J., C. M. Roberts, Sarah, \& Bond, Jason. (2012). Income Inequality, Alcohol Use, and Alcohol-Related Problems. American Journal of Public Health, 103(4), 64965.

Keane, Helen. (2009). Intoxication, harm and pleasure: an analysis of the Australian National Alcohol Strategy. Critical Public Health, 19(2), 135-142.

Krieger, N. (1994). Epidemiology and the web of causation: Has anyone seen the spider? Social Science \& Medicine, 39(7), 887-903

Laslett, Anne-Marie, Room, Robin, Ferris, Jason, Wilkinson, Claire, Livingston, Michael, \& Mugavin, Janette. (2011). Surveying the range and magnitude of alcohol's harm to others in Australia. Addiction, 106(9), 1603-1611

Latour, Bruno. (2004). Why Has Critique Run out of Steam? From Matters of Fact to Matters of Concern. Critical Inquiry, 2004, 225-248. 
Latour, Bruno. (2004a). How to Talk About the Body? The Normative Dimension of Science Studies. Body \& Soceity, 10(2/3), 205-229.

Latour, Bruno. (2005). Reassembling the Social: An Introduction to Actor-Network-Theory. Oxford: Oxford University Press.

Law, John. (2004). After Method: Mess in social science research. New York: Routledge Law, John. (2011a). Collateral Realities. In F. D. Rubio \& P. Baert (Eds.), The Politics of Knowledge. London: Routledge.

Law, John. (2011b). THE EXPLANATORY BURDEN: An Essay on Hugh Raffles's Insectopedia by Hugh Raffles. Cultural Anthropology, 26(3), 485-510

Law, John, \& Singleton, Vicky. (2003). Allegory and its others. In D. Nicolini, S. Gherardi \& D. Yanow (Eds.), Knowing in Organizations: a Practice Based Approach. New York: M.E. Sharpe.

Livingston, M., Laslett, A.-M, \& Dietze, P. (2008). Individual and community correlates of young people's high-risk drinking in Victoria. Drug and Alcohol Dependence, 98, 241-248.

Measham, Fiona. (2004). The decline of ecstasy, the rise of 'binge' drinking and the persistence of pleasure. The Journal of Community and Criminal Justice, 54(4), 309-326.

Mol, Annemarie. (1999). Ontological politics. In J. Law \& J. Hassard (Eds.), Actor Network Theory and after. Oxford: Blackwell.

Mol, Annemarie. (2002). The Body Multiple: Ontology in Medical Practice. Durham, N.C.: Duke University Press.

Mol, Annemarie, \& Law, Jown. (2002). Complexities: An Introduction. In J. Law \& A. Mol (Eds.), Complexities: Social Studies of Knowledge Practice (pp. 1-22). Durham \& London: Duke University Press.

Moore, David. (2011). The ontological politics of knowledge production: Qualitative research in the multidisciplinary drug field. In S. Fraser \& D. Moore (Eds.), The Drug Effect: Health, Crime and Society. Melbourne: Cambridge University Press.

National Health and Medical Research Council. (2009). Australian Guidelines to Reduce 
Health Risks from Drinking Alcohol. Canberra: Commonwealth of Australia.

Race, K. (2011). Drug effects, performativity and the law. International Journal of Drug Policy, 22, 410-412.

Rehm, Jürgen, Mathers, Colin, Popova, Svetlana, Thavorncharoensap, Montarat, Teerawattananon, Yot, \& Patra, Jayadeep. (2009). Global burden of disease and injury and economic cost attributable to alcohol use and alcohol-use disorders. The Lancet, 373(9682), 2223-2233.

Rehm, J., Baliunas, D., Borges, G.L.G., Graham, K., Irving, H., Kehoe, T., Parry, C.D., Patra, J., Popova, S., Poznyak, V., Roerecke, M., Room, R., Samokhvalov, A.V., \& Taylor, B. (2009). The relation between different dimensions of alcohol consumption and burden of disease: An overview. Addiction, 105, 817-843.

Rehm, J., Room, R., Monteiro, M., Gmel, G., Graham, K., Rehn, N., . . Jernigan, D. (2004). Alcohol use. In M. Ezzati, A. D. Lopez, A. Rodgers \& C. J. L. Murray (Eds.), Comparative Quantification of Health Risks. Global and Regional Burden of Disease Attributable to Selected Major Risk Factors: Volume 1 (Vol. 1, pp. 959-1108). Geneva: World Health Organization.

Ridolfo, B., \& Stevenson, C. (2001). The quantification of drug-caused mortality and morbidity in Australia, 1998. Canberra: Australian Institute of Health and Welfare.

Roche, A. M., P. Bywood, J. Borlagdan, B. Lunnay, T. Freeman, L. Lawton, A. Tovell and R. Nicholas (2008). Young people and alcohol: the role of cultural influences. Adelaide, National Centre for Education and Training on Addiction.

Room, Robin, \& Rossow, Ingeborg. (2001). The share of violence attributable to drinking. Journal of Substance Use, 6(4), 218-228.

Room, Robin. (2005). Stigma, social inequality and alcohol and drug use. Drug and Alcohol Review, 24(March), 143-155.

Rothman, Kenneth J. (1976). Causes. American Journal of Epidemiology, 104(6), 587-592.

Sjögren, Harmeet, Eriksson, Anders, Broström, Göran, \& Ahlm, Kristin. (2000).

Quantification of Alcohol-Related Mortality in Sweden. Alcohol and Alcoholism, 35(6), 601-61

Skog, O. L. E. JØRgen. (1996). Public health consequences of the J-curve hypothesis of alcohol problems. Addiction, 91(3), 325-33.

Thomson, N. \& Moore, D. (2014). Methamphetamine 'facts': The production of a 'destructive' 
drug in Australian scientific texts. Addiction Research and Theory (under review).

Vitellone, N. (2010). "Just another night in the shooting gallery?": the syringe, space and affect. Environment and Planning D: Society and Space, 28(5), 867-880

Vitellone, N. (2011). The science of the syringe. Feminist Theory, 12(2), 201-209.

Ward, Andrew C. (2009). The role of causal criteria in causal inferences: Bradford Hill's "aspects of association". Epidemiologic Perspectives \& Innovations, 6(2).

Weed, Douglas L. (2004). Precaution, Prevention and Public Health Ethics. Journal of Medicine and Philosophy 29(3), 313-332.

Weinberg, Darin. (2013). Post-humanism, addiction and the loss of self-control: Reflections on the missing core in addiction science. International Journal of Drug Policy, 24(3), 173-18

Woolgar, Steve. (2004). What happened to provocation in science and technology studies? History and Technology, 20(4), 339-349 